\title{
2018 Best Zone III Paper: Using the SCALE-UP Method to Create an En- gaging First Year Engineering Course (Extended Abstract)
}

\section{Dr. David Joseph Ewing, University of Texas, Arlington}

Earned a Bachelor of Science degree in Mechanical Engineering from Pensacola Christian College and a $\mathrm{PhD}$ in Mechanical Engineering from Clemson University. He spent several years teaching in a first year engineering program at Clemson University. He is now a Assistant Professor of Instruction at the University of Texas at Arlington, where he continues to teach first year engineering courses. Combined, he has been teaching first year engineering courses for over five years. His previous research involved thermal management systems for military vehicles. 


\title{
Using the SCALE-UP Method to Create an Engaging First Year Engineering Course (Extended Abstract) ${ }^{1}$
}

David J. Ewing - The University of Texas at Arlington

\begin{abstract}
To meet the growing demands for professional engineers, much emphasis has been placed on recruiting and retaining increasing numbers of engineering students. In response, the University of Texas at Arlington (UTA) performed a study and identified that students were ill-equipped to deal with the rigors of the engineering curriculum, particularly in the areas of problem solving, professional writing, and computer programming. Therefore, to address these areas, UTA has recently created a new first year engineering course that uses the Student-Centered Active Learning Environment with Upside-down Pedagogies (SCALE-UP) method. This presentation will include an overview of not only student performance broken down by several student groups but also early surveys showing student perception of the effectiveness of this method. The results will show that these pedagogies are effective in aiding students to learn the principles of engineering. In addition, student surveys will show that students respond favorably to the teaching strategies and learning environment implemented in the course.
\end{abstract}

\section{Keywords}

SCALE-Up, First Year Engineering, Active Learning, Peer Instruction

\section{Background}

UTA is in its second academic year of delivering a new first year engineering course designed specifically to address student success and retention. This course, named ENGR 1300 Engineering Problem Solving, was designed to aid students in acquiring solid engineering problem solving and communication skills and is intended to be taken during a student's first semester at UTA with a co-requisite of Pre-Calculus. This course was specifically developed to aid students in areas where they were found to be ill-prepared, with carry over into their performance in their upper-level classes. In order to adapt to the wide dispersion of learning styles, socio-economic backgrounds, and prior knowledge among students at UTA, ENGR 1300 utilizes the Student-Centered Active Learning Environment with Upside-down Pedagogies (SCALE-UP) method. This method, developed at NC State University ${ }^{1}$ and now utilized in many universities ${ }^{2}$, focuses on creating a highly active and collaborative environment that fosters interaction among student groups and among students and their instructors. The method has been shown to be effective due to its reliance on peer instruction, problem-based learning, teamwork skills, and a host of other "high touch" implementations.

\section{Methodology}

\footnotetext{
${ }^{1}$ This work is partially funded by the National Science Foundation, NSF STEP grant DUE \#0856796.

Proceedings of the 2017 ASEE Gulf-Southwest Section Annual Conference Organized by The University of Texas at Dallas Copyright (C) 2017, American Society for Engineering Education
} 
The SCALE-UP method required several modifications of the existing curriculum in order to facilitate implementation of active, problem-based learning strategies. First, a new classroom was constructed as shown in Figure 1. Students are arranged around around circular tables in teams of three, and marker boards are mounted around the room. This arrangement allows students to solve problems together, fostering peer instruction, which has been shown to be more effective in student success than traditional lecture-based styles. The arrangement also allows the professor to easily move among the students as they work on solving problems. This physical arrangement allows more one-on-one instructor interaction, providing for more personalization of the learning process.

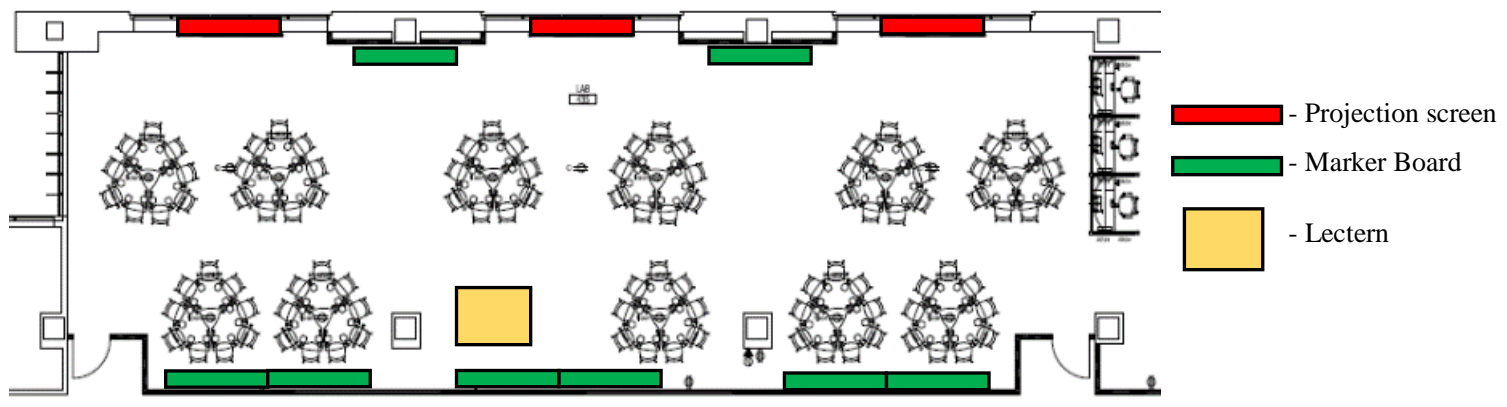

Figure 1. Classroom Layout

The second key strategy was the hiring of upperclassmen to act as in-class assistants. These assistants offer support during the class by essentially reducing the student-to-teacher ratio, again, providing more one-on-one instruction within the class. Also, students are often more comfortable asking the assistants rather than their teacher. Finally, in order to increase more oneon-one instruction and to relieve the increasing demand of office hours due to the number of students, the assistants conduct free tutoring sessions in the evenings where they help the students by guiding them through the problem-solving process. The in-class assistants are key contributors in fostering an environment where students are open to learning the material by asking questions of their peers.

Finally, the in-class teaching methodology had to be constructed focusing on active learning rather than traditional lecture style learning. Traditional lectures and passive learning techniques have shown to be decreasingly effective in student success and knowledge retention. Therefore, active, problem-based learning has been implemented in ENGR 1300. This method involves mini-lectures that leave time to focus more on students applying knowledge by solving problems within the classroom. Students work in their teams around the marker boards solving engineering mathematical and coding problems, allowing them to learn the principles of the class by solving real-world engineering problems, rather than simply relying on notes and examples from the professor. Also, the students have many tools to help them learn robust studying skills, such as a reading guide, interactive online tools, and additional challenging problems that they use to practice further with each other. Class time focuses on actively learning the process of problem solving with "high touch" interactions between the professor and in-class assistants, rather than passively learning through limited example problems solved by the professor alone.

\section{Results and Discussion}

Proceedings of the 2017 ASEE Gulf-Southwest Section Annual Conference

Organized by The University of Texas at Dallas

Copyright $\mathbb{C}$ 2017, American Society for Engineering Education 


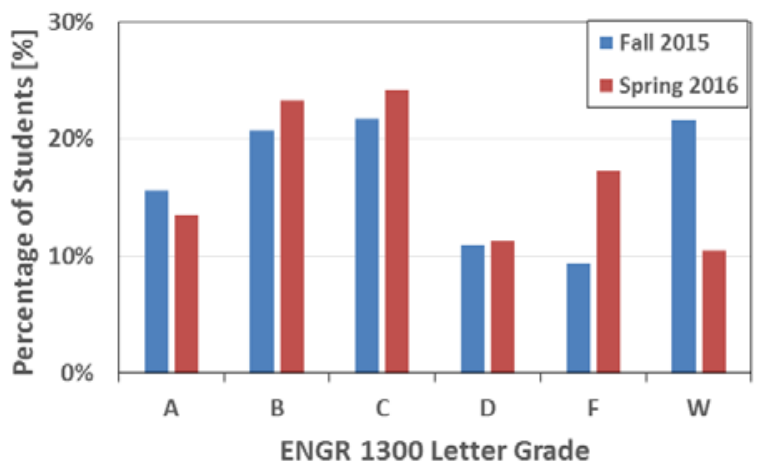

Figure 2. Letter grades for the Fall and Spring semesters

In exploring the matter of student success, the results that will be discussed are focused on success rates, defined as earning a $\mathrm{C}$ or better grade in the course, and grade distributions to aid in assessing the success of ENGR 1300. Figure 2 shows the letter grade distribution between the Fall and Spring semesters. The Fall success rate was $56.5 \%$ while the Spring success rate was $60.2 \%$. Even though ENGR 1300 is typically a first semester course, UTA saw an increase in success rate. In order to more fully understand the reason for this increase, we will explore the potential factors that may contribute to this increase, such as admission status, declared major, and student perception.

Before addressing these factors, we must particularly address the difference in the withdrawal rate. ENGR1300 was first taught in Fall 2015, replacing a traditional one credit hour introduction to engineering course. Anecdotal evidence from the students indicated that they assumed that ENGR 1300 was similar to the one credit course it replaced and its lack of rigor. Therefore, they insufficiently prepared for the first exam, resulting in very low test scores. To combat this perception for the Spring semester, a low-stakes quiz was added before the first exam. The addition of this self-diagnostic tool, along with the natural change on student perception of ENGR 1300, let to a much lower withdrawal rate in the second semester.
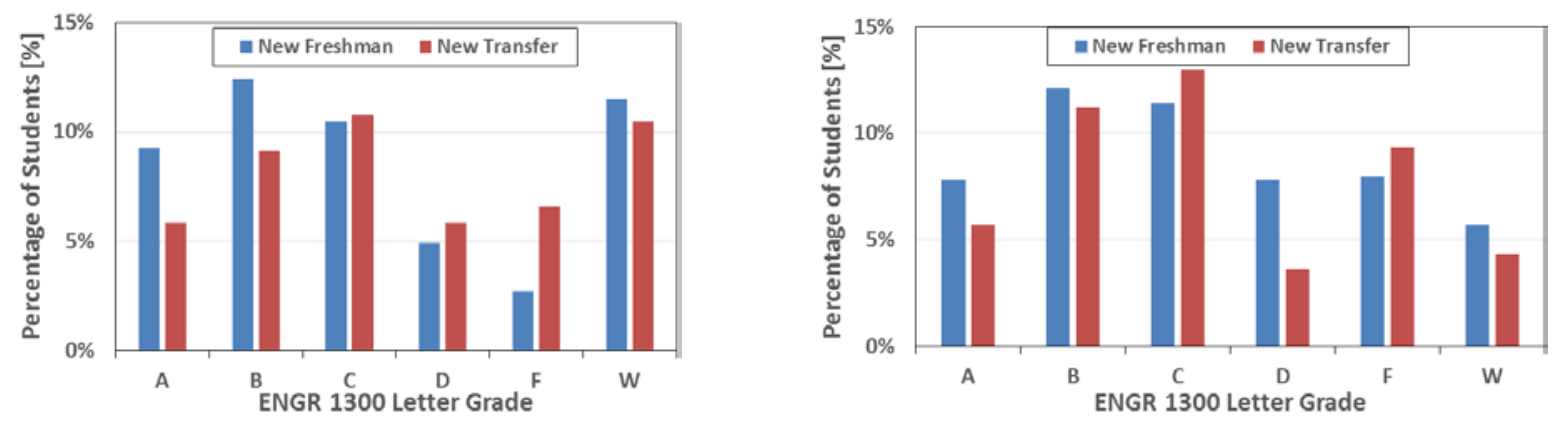

Figure 3. Comparative analysis between the letter grades of admission types for Fall 2015 (left) and Spring 2016 (right)

In order to study the potential influence admission status, we will focus on the findings in Figure 3 and Figure 4. First time first year students outperformed their transfer counterparts as seen in Figure 3. Also, the first time first year students had better success rates, $55.6 \%$ and $51.1 \%$, than the transfer students, $44.4 \%$ and $48.9 \%$. In order to more fully understand the reason for the disparity, Figure 4 shows the success rates for the departments represented in ENGR 1300. Figure 4

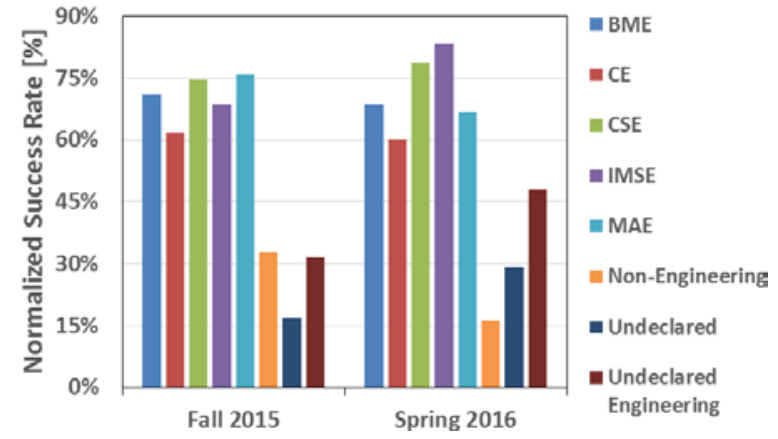

Figure 4. Success rates for the different majors represented in ENGR 1300 shows a much higher success rate for those 
associated with an engineering department, while those not associated with a specific engineering department have substantially lower success rates. More analysis is needed to determine the root cause for the lower success rates in our undeclared populations.

Finally, student perception of the class was explored. A survey was distributed among the students at the end of the semester to allow them a way to provide feedback on

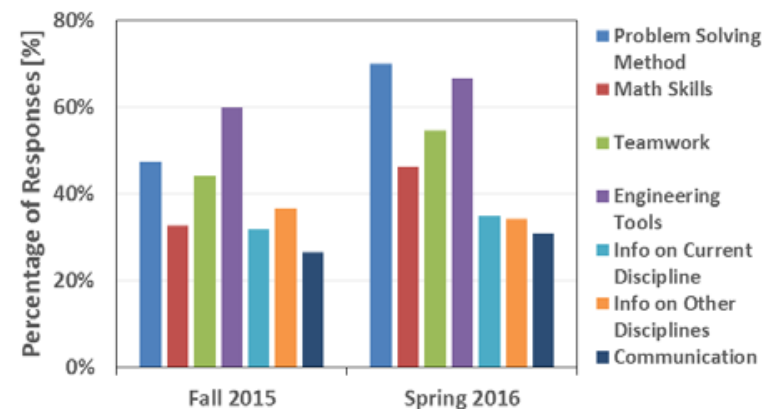

Figure 5. Survey results for what the students reported learning their perception of the effectiveness of course pedagogy and as a way to ascertain their own sense of how they improved certain skills. Figure 5 shows the results of what students felt they improved on in the course, chosen from a pre-prepared list of responses with multiple choices allowed. Students overwhelmingly and increasingly respond positively to engineering skills, including teamwork, engineering tools

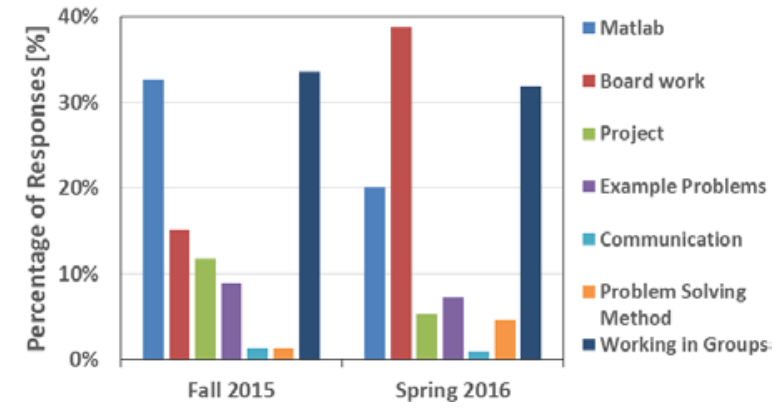

Figure 6. Survey results of student's free form reporting what they found helpful (MatLab), math skills, and problem solving methods.

Figure 6 specifically asked what one particular method was most helpful in the class, with free response, open-ended answers. Most notably the students overwhelmingly responded positively to such active, problem-based learning and peer instructional procedures such as MatLab, marker board work (active learning), and working in groups (peer instruction).

\section{Conclusion and Future Work}

In conclusion, ENGR 1300 has shown to be an effective course for first year engineering students by using the SCALE-UP method to aid students in acquiring practical engineering skills. This fact can be seen not only in the increase of success rates but also the overwhelming positive responses of student perception. Further assessment work will need in order to understand the role of student enrollment background as well as math placement to aid in enhancing the effectiveness of this course.

\section{References}

1 Beichner, R., J. Saul, R. Allain, D. Deardorff, and D. Abbot, "Introduction to SCALE-UP: StudentCentered Activities for Large Enrollment University Physics,” presented at the Annual meeting for the American Society for Engineering Education, St. Louis, MS, 2000.

2 Ingram, B., M. Jesse, S. Fleagle, J. Florman, and S. Van Horne, Cases on Higher Education Spaces: Innovation, Collaboration, and Technology, IGI Global, Hershey, PA, 2013, pg. 165-185. 
David J. Ewing -Earned a Bachelor of Science degree in Mechanical Engineering from Pensacola Christian College and a PhD in Mechanical Engineering from Clemson University. He spent several years teaching in a first year engineering program at Clemson University. He is now a senior lecturer at the University of Texas at Arlington, where he continues to teach first year engineering courses. Combined, he has been teaching first year engineering courses for over five years. His previous research involved thermal management systems for military vehicles. 